\title{
Kajian Konsep Aksesibilitas pada SLB Negeri Bekasi Jaya
}

\author{
*Ghafari Yahya ${ }^{1}$, Finta Lissimia ${ }^{2}$ \\ ${ }^{1,2}$ Arsitektur, Fakultas Teknik, Universitas Muhammadiyah Jakarta, Indonesia \\ abangari18@gmail.com \\ *Alamat korespondensi, Masuk: 21 Agust. 2020, Direvisi: 04 Sept. 2020, Diterima: 16 Sept. 2020
}

\begin{abstract}
ABSTRAK: Sekolah adalah sebuah jejang pendidikan yang bisa membuat manusia kepada kualitas kehidupan bermasyarakat yang lebih sempurna. Aksesibilitas adalah konsep yang dapat memudahkan manusia atau seseorang untuk mencapai objek di lingkungan sekitarnya. Aksesibilitas yang memadai akan menyetarakan antara pengguna berkebutuhan khusus dengan pengguna dengan kondisi normal pada sekolah. Arsitektur berperan sebagai ruang aktivitas manusia yang menciptakan keselarasan antara ruang yang berada di dalam dan di luar. Ruang dalam dan ruang luar dapat terbentuk karena persepsi dan imajinasi manusia sebagai pengguna. Metode yang peneliti gunakan adalah metode menyurvei data sekaligus mengumpulkan data dan studi literatur. Hasil dari penelitian ini adalah kelayakan akses yang menunjang kegiatan maupun pada sekolah luar biasa yang diterapkan pada objek yang diteliti.
\end{abstract}

Kata kunci: Arsitektur, Konsep aksesibilitas, Sekolah luar biasa

\begin{abstract}
School is an education level that can deliver people to a better quality of social life. The concept of accessibility is the level of convenience achieved by a person with an object in his environment. Adequate accessibility will equalize users with special needs with users with normal conditions at school. Architecture acts as a space for human activities that creates a relationship between inner and outer space. Inner space and outer space can be formed due to the perception and imagination of humans as users. The method used is a data collection method, data collection process by interview and literature study. The result of this research is the feasibility of access to support activities and special schools that are applied to the object under study.
\end{abstract}

Keywords: Architecture, Accessibility concepts, Extraordinary school

\section{PENDAHULUAN}

Sekolah adalah sebuah wadah bagi masyarakat untuk mendapatkan wawasan dan mendapat kualitas bermasyarakat lebih sempurna. Hingga sekarang ini pemerintah mewajibkan siswa/siswi untuk menempuh dalam waktu 12 tahun wajib belajar tidak terkecuali kaum difabel. Kaum disabilitas adalah orang yang memiliki kekurangan baik dari segi fisik, mental, ataupun kognitifnya. Bangunan sekolah luar biasa yang ada umumnya masih belum ramah dalam segi aksesibilitas. Aksesibilitas diperlukan untuk memberikan kemudahan dalam proses Pendidikan pada anak difabel sehingga tujuan pendidikan dapat tercapai [1].

Dalam merancang sebuah bangunan pendidikan terutama bangunan sekolah disabilitas harus mementingkan standar bangunan yang berlaku. Ketentuan atau standar yang digunakan adalah Permen no. 30 yang membahas teknis fasilitas dan aksesibilitas pada bangunan gedung dan lingkungan. Beberapa teknis yang menjadi acuan bagi kegiatan pembangunan gedung, yang dimaksudkan membuat pelaksanaan konstruksi dan teknis serta pemanfaatan lingkungan dan gedung yang mudah digunakan atau dilalui bagi semua penyandang disabilitas terutama anak tunanetra dan tunadaksa. Pembangunan yang harus diperhatikan adalah fasilitas dan aksesibilitas yang meliputi kemudahan, keselamatan, kemandirian dan kegunaan [2,3].

Tujuan yang ingin diketahui peneliti adalah untuk mengetahui rancangan sekolah kejuruan difabel dan mengetahui penerapan konsep aksesibilitas pada sekolah kejuruan difabel.

\section{Difabel dan disabilitas}

Pengertian difabel atau disabilitas secara umum adalah sama yaitu sebutan untuk seseorang yang memiliki kemampuan fisik dan mental yang abnormal. Namun penggunaan istilah difabel atau 
disabilitas masih membuat pro kontra baik di Indonesia maupun dunia [4].

Difabel adalah seorang yang memiliki kekurangan fisik atau kelainan pada mental yang bersifat mengganggu atau sebuah hambatan untuk seorang individu dan bersifat mengganggu untuk melakukan kegiatan sehari-hari secara normal [4].

Definisi difabel adalah suatu ketidaknormalan atau kehilangan baik itu bersifat psikologis, fisiologis, maupun kehilangan struktur atau fungsi dari anatomis [5].

Pengertian disabilitas adalah individu yang termasuk kedalam gangguan cacat mental, gangguan cacat fisik ataupun gabungan gangguan cacat fisik dan mental (UU 4/1997) [6].

Definisi disabilitas adalah ketidakseimbangan interaksi antara kondisi biologis dan lingkungan sosial (CRPD/Konvensi Hak dan Penyandang Disabilitas) [6].

Aksesibilitas berdasarkan pasal 1 ayat 4 undang - undang no.4 tahun 1997 adalah sebuah desain atau perencanaan yang memudahkan aktivitas bagi penyandang cacat guna membangun kesetaraan dalam aspek kehidupan. Aksesibilitas bisa juga diartikan sebagai kemudahan yang bisa dicapai oleh kaum disabilitas ke suatu ruang atau objek lingkungan disekitarnya. Aksesibilitas juga harus memfokuskan pada desain fasilitas yang memudahkan bagi penderita cacat untuk menggunakan kursi roda yang bisa melalui trotoar atau naik kendaraan umum dengan aman [6].

Dalam Declaration on the rights of disable person membuat penegasan penyandang cacat bahwa mereka berhak menjadi mandiri atau tergantung dari pihak lain. Mereka juga memiliki hak untuk mendapatkan pelayanan psikologis, pendidikan, medis, kesempatan kerja dan semua jenis pelayanan yang bisa membuat mereka menjadi berkembang seperti manusia normal lainnya

Dari semua pendapat yang peneliti tulis dapat disimpulkan bahwa aksesibilitas adalah kemudahan yang disediakan untuk mengakses layanan, prasarana dan sarana baik fisik dan non fisik bagi penderita cacat sehingga dapat mandiri dan tercapai kesetaraan hak di berbagai bidang dan aspek kehidupan serta penghidupan. Jadi dikatakan aksesibilitas jika memenuhi keempat asas aksesibilitas yaitu keselamatan, kemudahan, kegunaan dan kemandirian.

Untuk mendapatkan gambaran mengenai aksesibilitas di sekolah luar biasa dilakukan survei sekolah yaitu SLB Negeri Bekasi Jaya. Selanjutnya keadaan bangunan di sekolah tersebut dibandingkan dengan standar yang ditentukan oleh Peraturan menteri pekerjaan umum no. 14 tahun 2017 ada beberapa item perencanaan ruang yang harus dijadikan evaluasi untuk membangun sebuah gedung/bangunan [7,8]. Namun, penulis beranggapan ada 6 item yang hanya dapat diwujudkan di bangunan sekolah, yaitu :

- Jalur pemandu/guding block

- Ukuran dasar ruang

- Jalur pedestrian (Entrace)

- Ramp

- Toilet/WC

- Jalur evakuasi

\section{METODE PENELITIAN}

Terdapat berbagai metode yang digunakan dalam penyusunan penelitian konsep aksesibilitas pada Sekolah Luar Biasa (SLB) Negeri Bekasi Jaya di Bekasi. Metode tersebut dijelaskan sebagai berikut:

\section{Pengumpulan Data}

Dalam penyusunan laporan ini, pengumpulan data dilakukan dengan cara seperti:

\section{Wawancara}

Merupakan metode pengumpulan data yang dilakukan dengan cara berupa tanya jawab dengan narasumber. Narasumber dalam pengumpulan data ini adalah dengan mewawacara guru yang mengajar sekolah luar biasa.

\section{Studi Literatur}

Pengumpulan data berdasarkan literatur dan referensi terhadap data yang berkaitan secara langsung maupun terhadap konsepsi penyusunan, mulai dari buku, jurnal, majalah, serta artikel pendukung lain yang valid pada situs pencarian data di internet.

\section{Observasi Lapangan}

Kegiatan ini berupa pengamatan yang dilakukan terhadap bangunan dan lokasi yang akan digunakan untuk merencanakan perancangan. Observasi dilakukan langsung terhadap keadaan eksisting di lapangan sehingga dapat ter gambarkan suasana sebenarnya terhadap proses penyusunan.

\section{Kompilasi Data}

Mengelompokkan data yang terkumpul berdasarkan jenis permasalahan yang nantinya akan dipilih sesuai dengan penelitian konsep aksesibilitas pada sekolah luar biasa di Bekasi.

\section{Analisis}


Melakukan proses penguraian dan menganalisis tentang penelitian konsep aksesibilitas pada sekolah luar biasa di Bekasi, dengan tujuan untuk memecahkan masalah yang sudah dirumuskan.

Berikut proses analisis dalam penelitian yang berjudul Konsep Aksesibilitas pada Sekolah Kejuruan Difabel pada SLB Negeri Bekasi Jaya yang terlihat pada Gambar 1 .

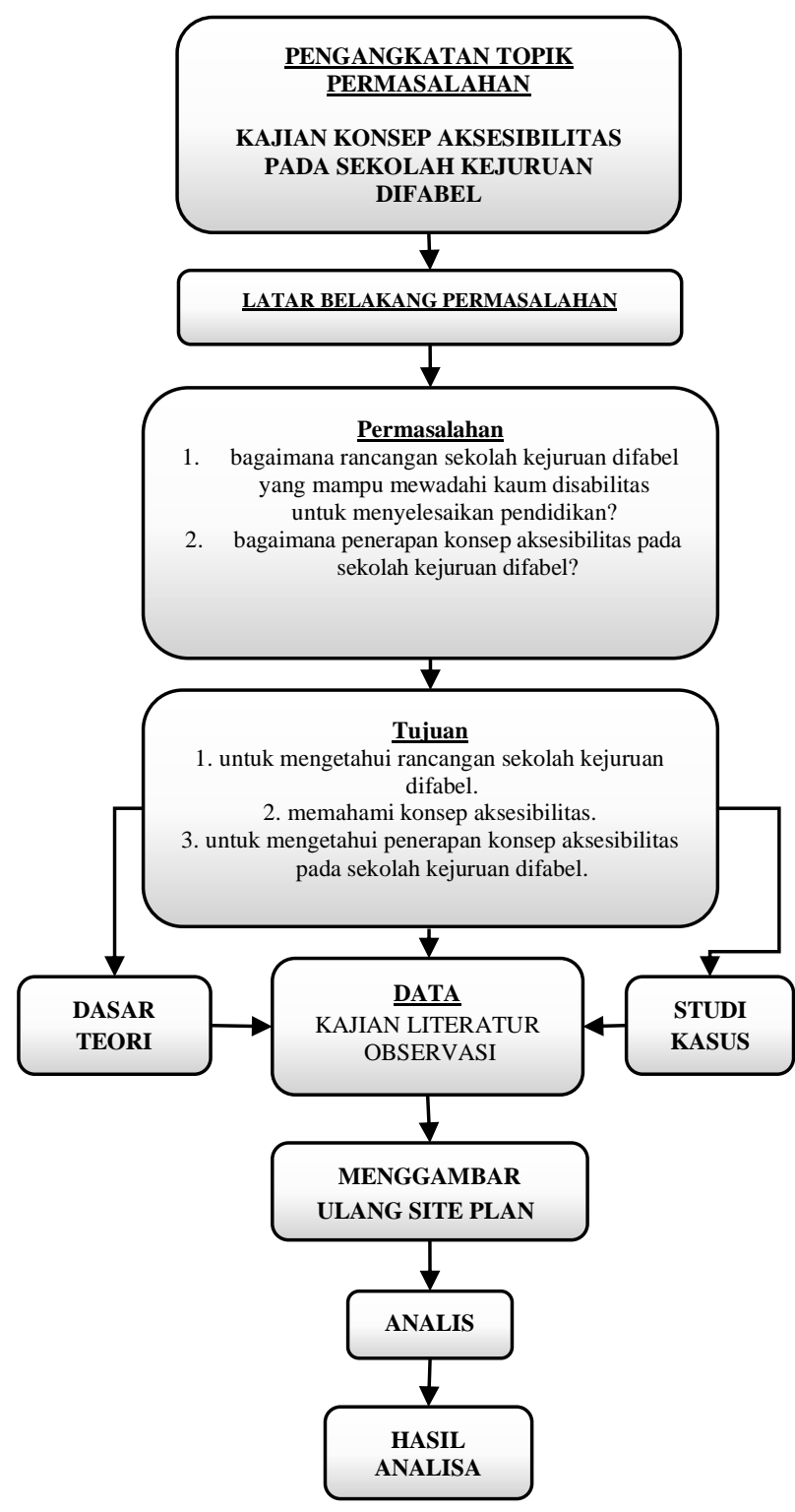

Gambar 1. Skema analisis data

\section{HASIL DAN PEMBAHASAN}

\section{SLB Negeri Bekasi Jaya}

Sekolah Luar Biasa (SLB) Negeri Bekasi jaya merupakan sekolah luar biasa yang memiliki tujuan antara lain adalah membantu peserta didik berkebutuhan khusus untuk mengembangkan pengetahuan, pengembangan sikap dan keterampilan individual agar dalam menjalin hubungan bermasyarakat atau bersosial menjadi lebih baik dan bisa berkomunikasi dengan masyarakat layaknya manusia normal. SLB tersebut berlokasi di JL. Mahoni Raya blok A16 nomor 171, Rt.002/Rw.009, Bekasi Jaya, Kec. Bekasi Timur, Kota Bekasi, Jawa Barat 17112. Sekolah ini memiliki beberapa ruangan, diantaranya ruang kelas, ruang menjahit, ruang tata boga, salon, toilet, dll. Ukuran tiap ruangan memiliki perbedaan, pada ruang kelas umumnya memiliki ukuran rata - rata 6 x $5 \mathrm{~m}$, salon $5 \times 5 \mathrm{~m}$, ruang tata boga $3 \times 6 \mathrm{~m}$, dan ruang menjahit $5 \times 5 \mathrm{~m}$. Guiding block atau jalan pemandu menghubungkan ke tiap ruang kelas hanya terdapat di lantai dasar, sedangkan untuk lantai di atasnya tidak ditemukan.

\section{Ukuran Dasar Bangunan}

Ukuran dasar sebuah ruangan 3 dimensi adalah peralatan yang digunakan pengguna disabilitas dan ruang yang dibutuhkan dengan panjang, lebar dan tinggi yang mengacu pada standar yang dibutuhkan. Masing-masing ruang yang digunakan atau dipakai oleh pengguna disabilitas yang ada di dalam bangunan harus disesuaikan dengan fungsi kemudian ditetapkan kapasitas maksimal penggunanya. Ada 3 persyaratan yang harus dipenuhi yaitu :

a. Ukuran dasar maksimum dan minimum yang digunakan dalam pedoman ini dapat ditambah atau dikurangi sepanjang kebutuhan aksesibilitas dapat tercapai

b. Ukuran dasar ruang ditetapkan dengan mempertimbangkan fungsi.

c. Pengguna dan pengunjung harus memenuhi ruang gerak yang dibutuhkan.

\section{Jalur Pemandu atau Guiding Blok}

Guiding block adalah ubin atau keramik yang didesain khusus seperti bulatan-bulatan dan garis lurus yang diperuntukkan untuk pejalan kaki yang memiliki kebutuhan khusus. akses menuju kelas dan keluar kelas memiliki batasan elevasi, Pada bagian lantai sekolah dilengkapi dengan guiding Block garis kuning penunjuk jalan bagi tuna netra. guiding block hanya terdapat di lantai dasar saja, sedang untuk di lantai 2 tidak ada guiding block. Garis panah berwarna oranye adalah guiding block yang tersedia di setiap lantai menuju ruang kelas dan ruang lainnya. Sirkulasi yang di buat dengan guiding block dapat memudahkan siswa/i tuna netra yang akan menuju ruang kelas dan ruang lainnya. 


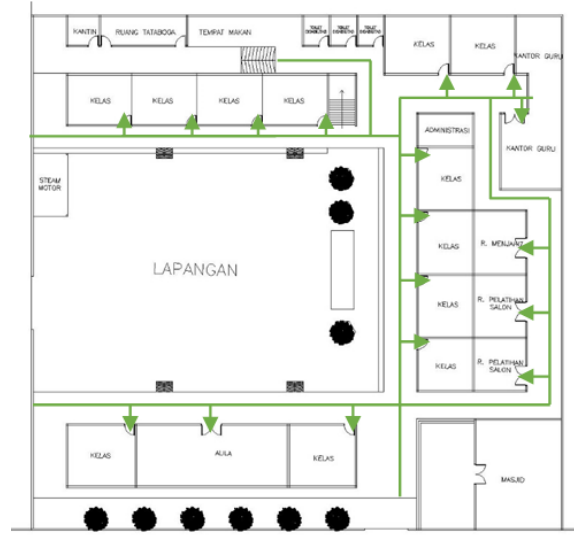

Gambar 2. Jalur guiding block

\section{Jalur Pedestrian (entrance)}

Jalur pedestrian adalah jalur yang digunakan untuk membantu penyandang disabilitas baik tuna daksa maupun tunanetra. Pintu masuk sekolah dapat diakses dari dua arah, yaitu dari pintu depan dan dari pintu samping. Pada bagian pintu samping siswa/siswi tunadaksa yang menggunakan kursi roda ketika masuk ke area sekolah harus dibantu karena ramp yang tersedia belum standar atau masih terlalu tinggi. Dan pada bagian pintu depan ramp yang tersedia sudah cukup landai untuk siswa/siswi tunadaksa yang menggunakan kursi roda. Handrail ditemukan pada tiap ruang kelas dan di luar ruang kelas di lantai 2.
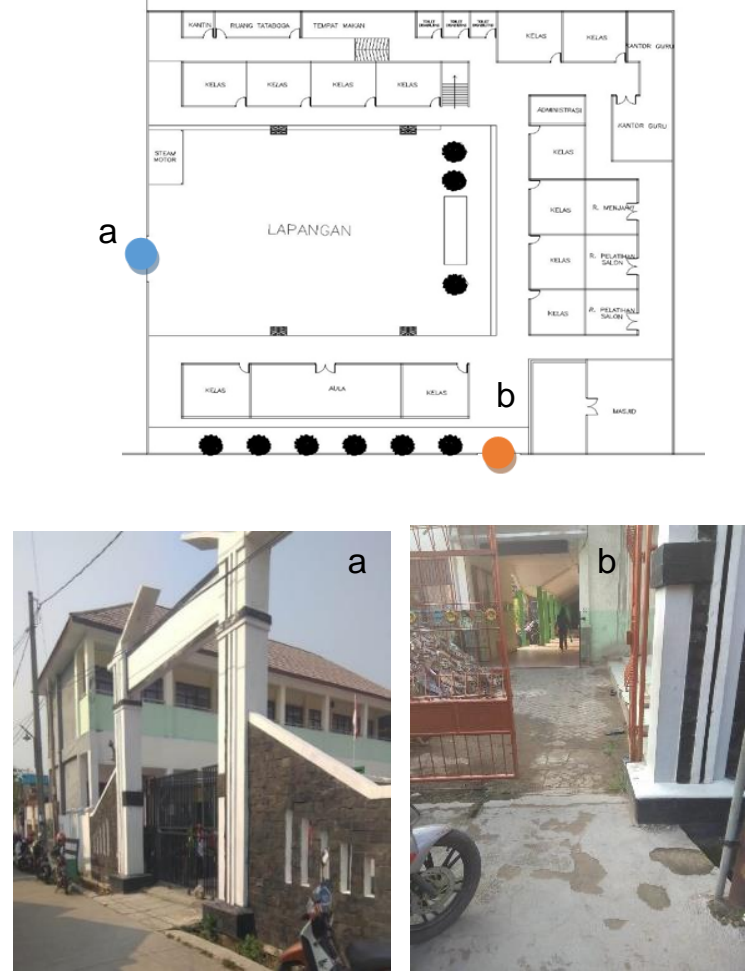

Gambar 3. a) Pintu depan; b) Pintu samping

\section{Ramp}

Ramp adalah bidang miring yang bangun atau dipasang untuk menggantikan tangga. Permukaan yang landai memudahkan pengguna disabilitas atau pengguna kursi roda serta orang yang sedang mendorong bayi atau beda beroda lainnya agar lebih mudah dalam mengakses dan masuk ke dalam sebuah bangunan. Ramp yang tersedia pada SLB belum memenuhi standar dengan kemiringan pada ramp dalam bangunan. Kemiringan ramp atau elevasi dari awalan hingga akhiran maksimum $6^{\circ}$ dan panjang tidak melebihi 9 meter/ $900 \mathrm{~cm}$. panjang suatu ramp dengan kemiringan yang lebih rendah maka yang terjadi adalah kemiringan akan curam. Bordes pada perbedaan level awalan dan akhiran sebuah ramp harus datar atau harus bebas agar memudahkan pengguna kursi roda untuk melaluinya.

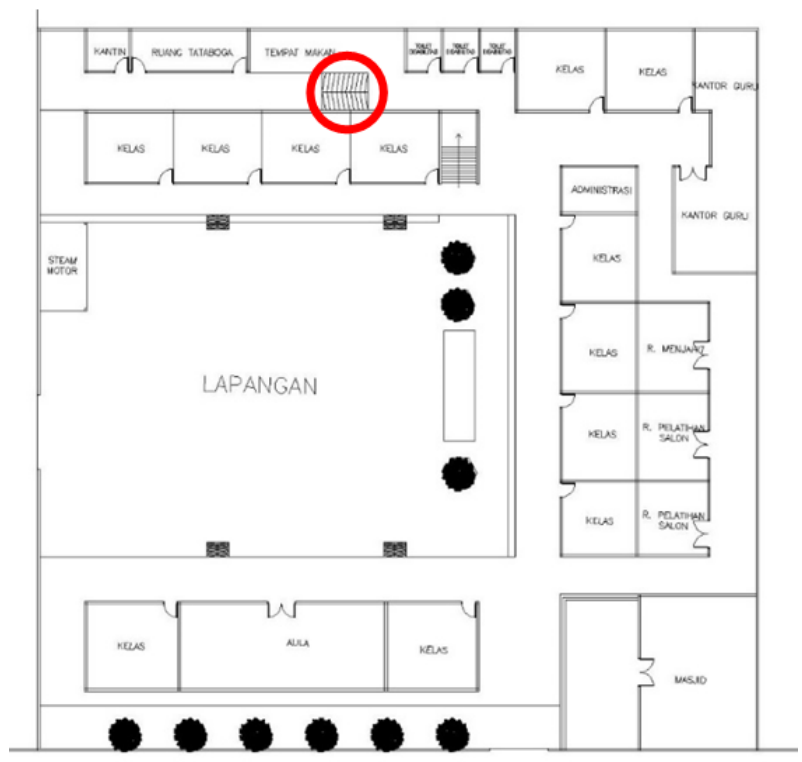

Gambar 4. Ramp pada denah
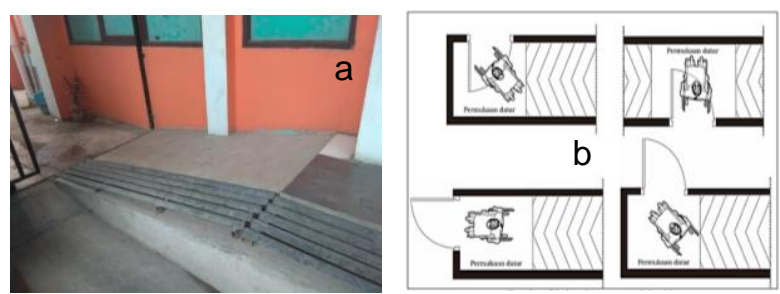

Gambar 5. a) Ramp menuju kantin; b) Ramp untuk koridor

\section{Jalur evakuasi}

Pada sekolah juga terdapat titik kumpul ketika ada pelatihan reka bencana alam atau untuk keperluan lainnya. Titik tersebut berada pada 
lapangan dan dekat dengan pintu depan sekolah. Titik berwarna oranye adalah titik dimana semua siswa dan guru berkumpul, garis panah berwarna biru adalah jalur sirkulasi evakuasi dari setiap kelas atau ruangan menuju assembly point/titik kumpul dan titik berwarna hijau adalah pintu keluar dari setiap ruangan. Semua yang tergambar adalah analisis yang lakukan peneliti berdasarkan pengamatan.

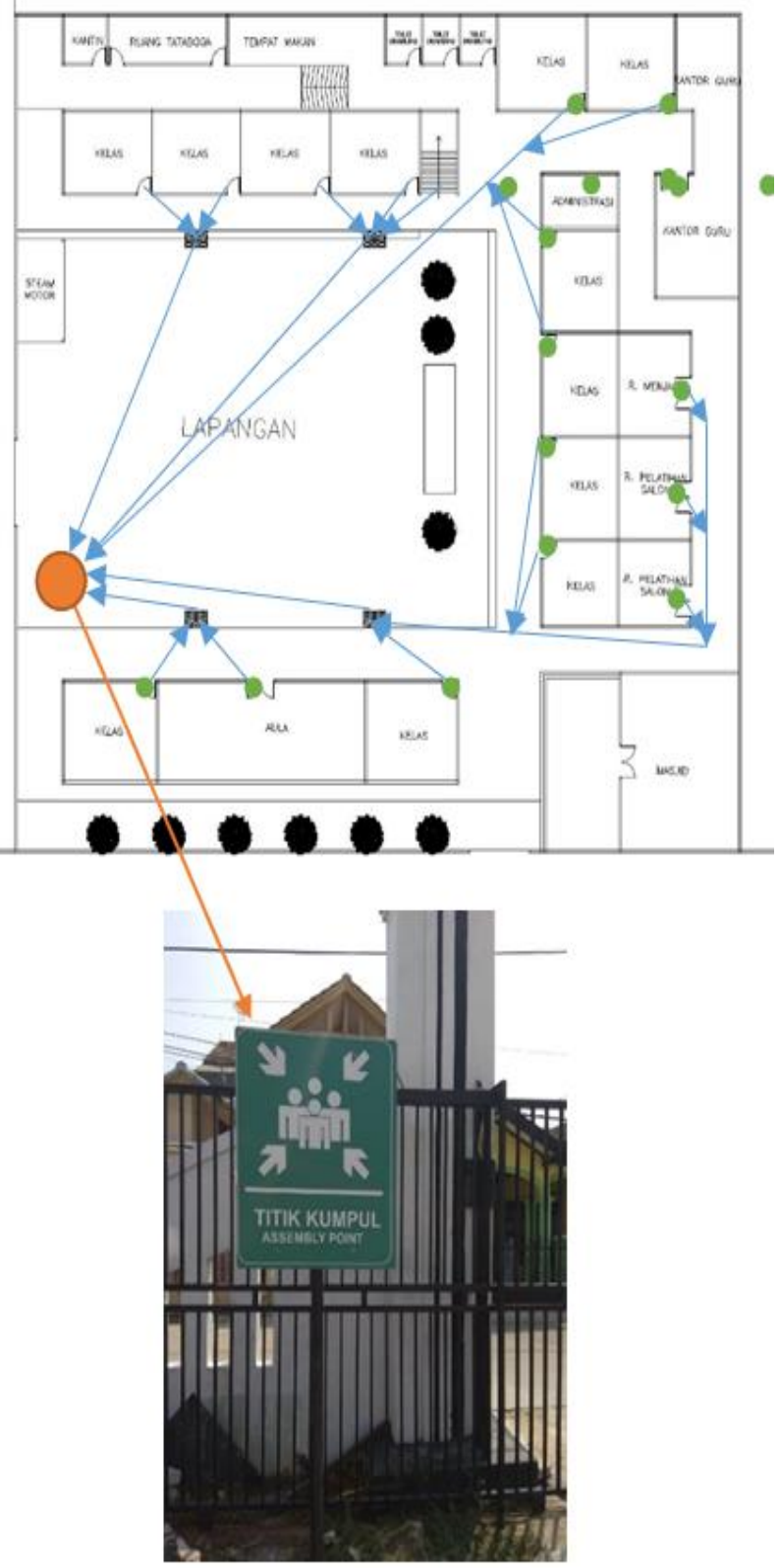

Gambar 6. Jalur evakuasi dan titik kumpul

\section{Akses kegiatan bersama}

Seperti pada umumnya, pada bagian tengah pada umumnya, SLB mempunyai lapangan yang digunakan untuk kegiatan upacara, olahraga, berkemah dll. Lapangan tersebut cukup luas untuk menampung seluruh kegiatan yang dilakukan siswa/siswi SLB tersebut. Pada gambar terlihat warna pink yang sudah diberi tanda yang artinya kegiatan di lapangan hanya sebatas area warna tersebut.

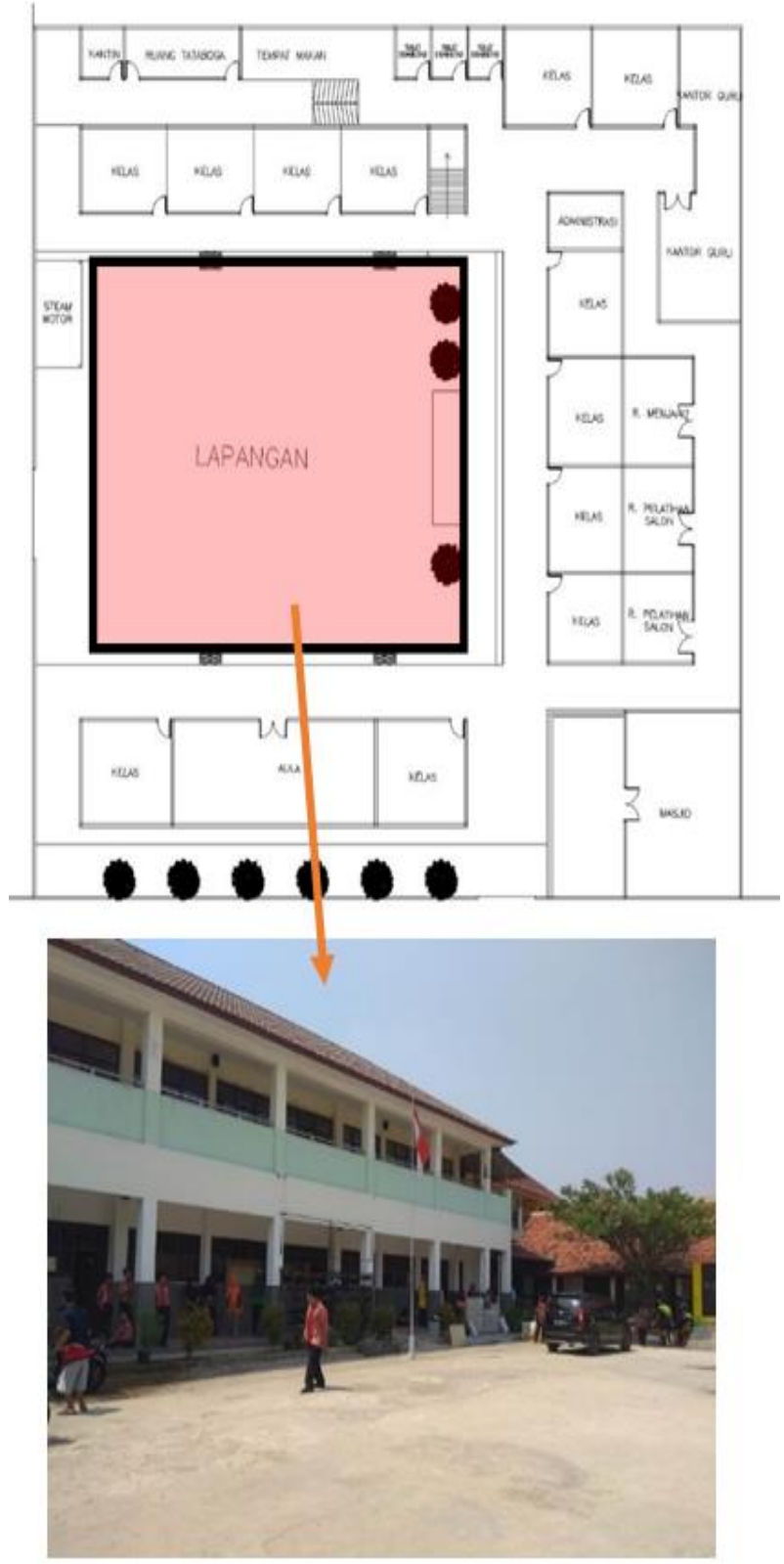

Gambar 7. Lapangan SLB

SLB Negri Bekasi Jaya juga memiliki fasilitas yang berbeda pada sekolah umumnya yaitu steam motor/ tempat pencucian motor. Steam motor ini dikelola oleh sekolah dan yang bertugas sebagai pencuci tersebut juga berasal dari siswa sekolah tersebut yang tentunya sudah dilatih. 

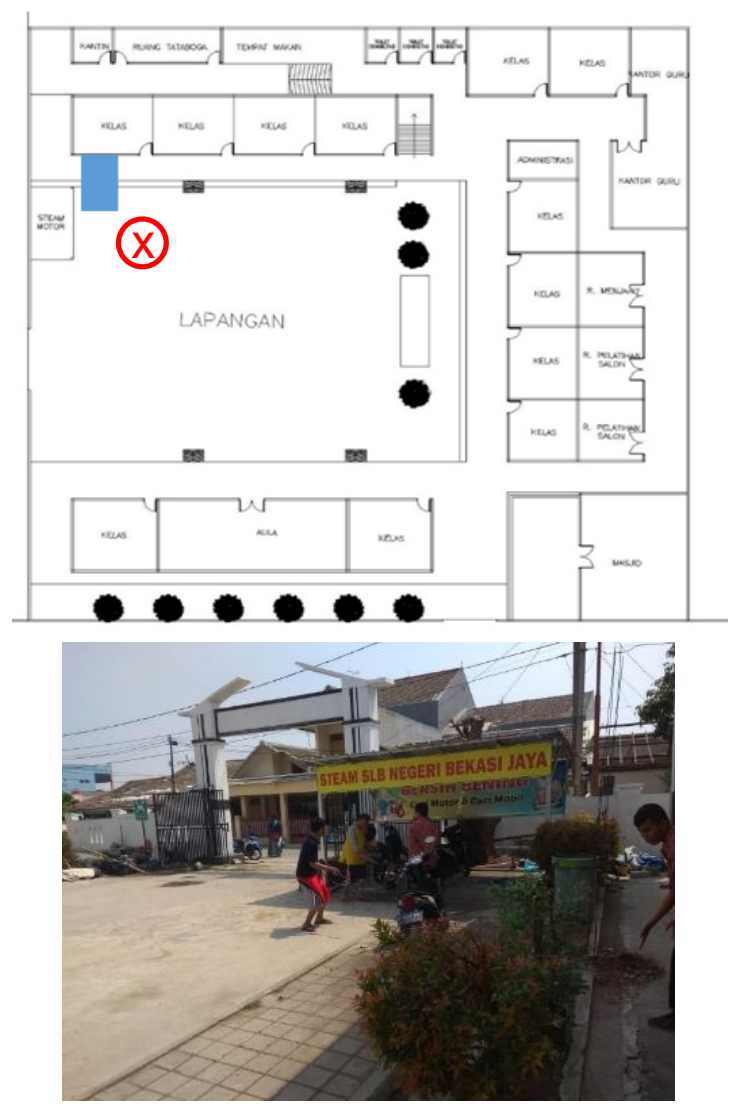

Gambar 8. X) Pelatihan steam motor

\section{Analisis akses ruangan dalam bangunan}

Pada SLB Negeri Bekasi Jaya juga memiliki fasilitas pelatihan salon yang diberikan khusus dari sekolah. Pelatihan dilakukan rutin setiap hari Senin sampai kamis yang diajarkan masing-masing wali murid. Ruangan ini berukuran $5 \mathrm{~m}$ x $5 \mathrm{~m}$.

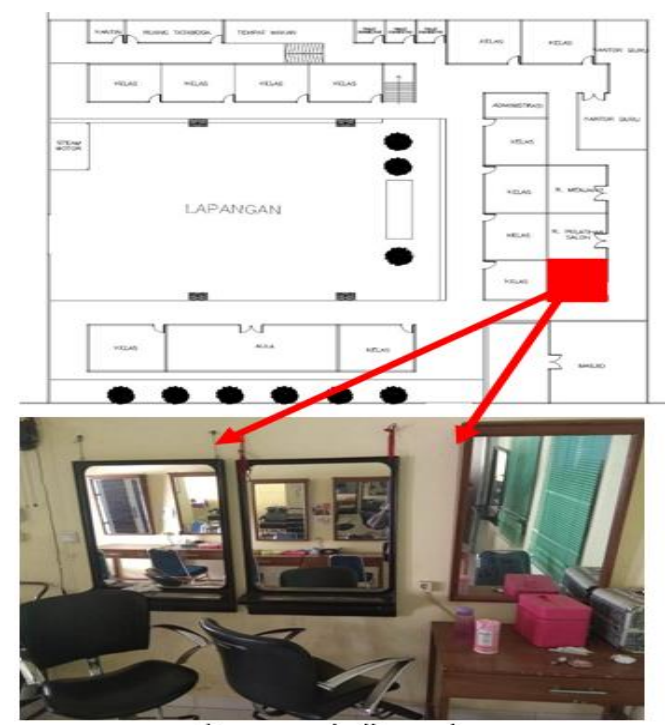

Gambar 9. Pelatihan salon
Pada dinding ruangan pelatihan salon terdapat langkah-langkah/cara untuk melakukan kegiatan salon. Tentunya kegiatan tersebut harus dalam pengawasan guru atau wali kelas yang mengajar.

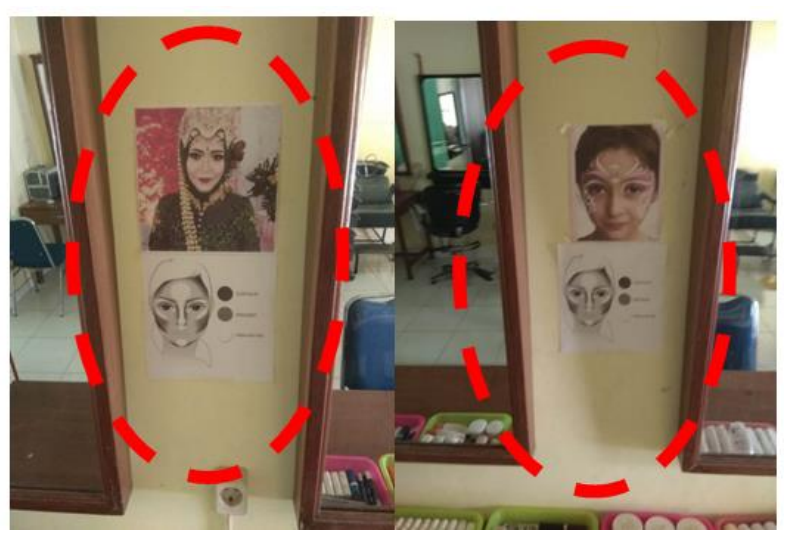

Gambar 10. Tutorial pelatihan salon

Pada ruangan selanjutnya fasilitas yang disediakan oleh SLB negeri Bekasi jaya ini adalah pelatihan menjahit. Pelatihan ini harus dalam pengawasan yang ketat agar siswa/siswi yang dilatih tidak terjadi kecelakaan.

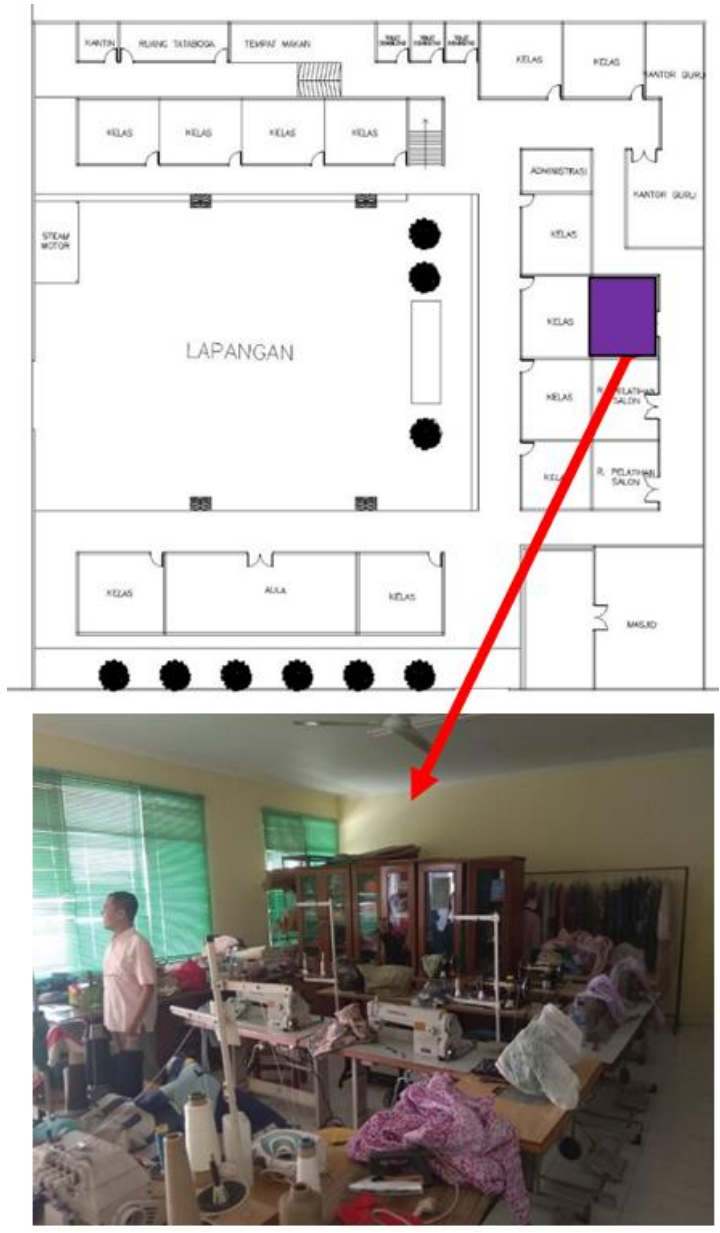

Gambar 11. Ruang pelatihan menjahit 
Fasilitas selanjutnya yang diberikan oleh SLB negeri Bekasi jaya adalah ruangan pelatihan tata boga/latihan memasak. Ruangan ini berdiameter sekitar $3 \mathrm{~m} \times 6 \mathrm{~m}$. ruangan ini berfungsi untuk melatih siswa dan siswi untuk memasak, membuat makanan dll.

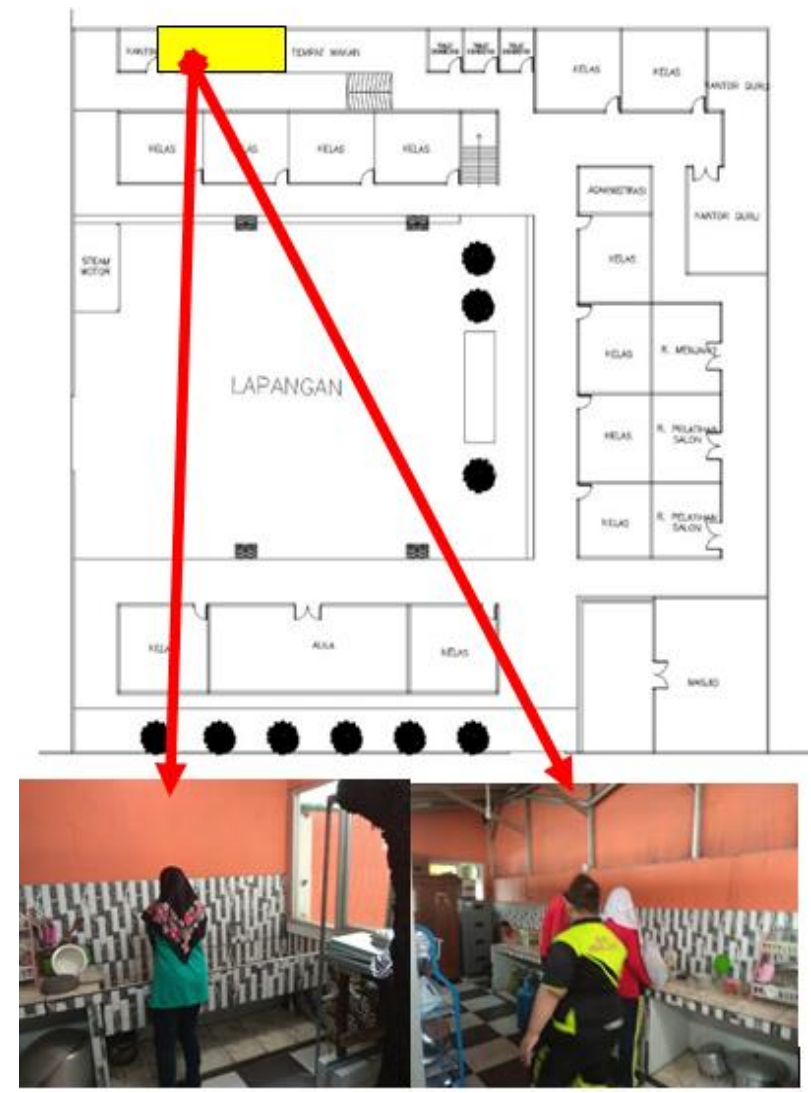

Gambar 12. Ruang pelatihan Tata boga

\section{Analisis handrail}

Pada bagian tembok juga terdapat sebuah alat bantu Handrail untuk penunjuk kelas agar siswa tidak salah masuk ke kelas. Alat bantu ini terbuat dari aluminium silinder dan terdapat diseluruh tembok menuju kelas. Handrail yang terpasang juga sudah memenuhi standar

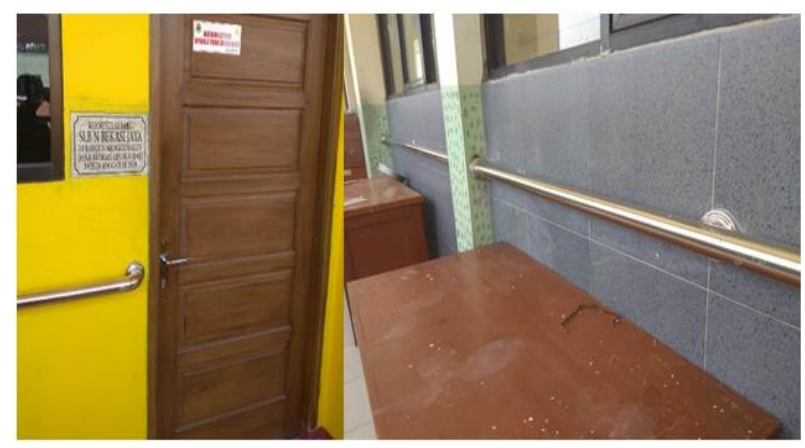

Gambar 13. Handrail/pegang rambat

\section{Toilet}

Ruang sanitasi yang dapat diakses oleh semua orang tanpa terkecuali penyandang disabilitas, orang tua, anak-anak, dan wanita hamil) pada bangunan gedung atau fasilitas umum yang lainnya. Toilet atau WC yang digunakan pada SLB negeri Bekasi jaya masih ada beberapa kekurangan untuk pemakai difabel. Seperti pegangan rambat/handrail yang kurang memenuhi syarat. Selain dari handrail menurut analisis semua sudah memenuhi syarat. hanya saja toilet yang diamati kurang terawat dan membuat toilet terlihat kotor.

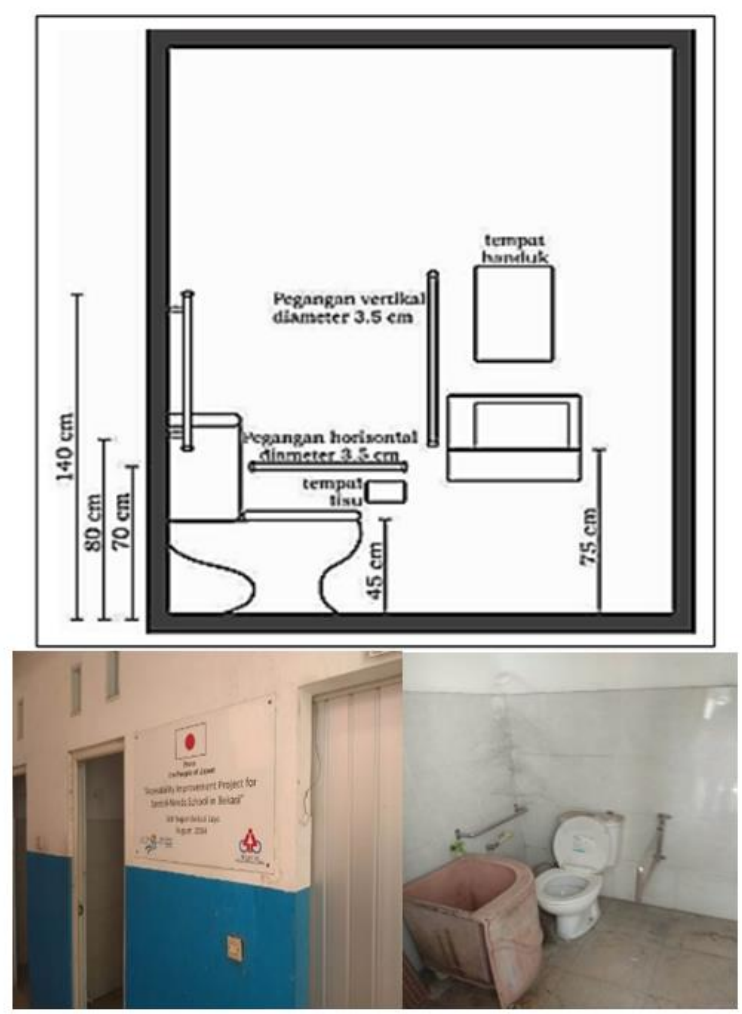

Gambar 14. Toilet disabilitas

\section{KESIMPULAN DAN SARAN}

Aksesibilitas berdasarkan pasal ayat 4 UU No. 4 tahun 1997 mengartikan aksesibilitas adalah kemudahan fasilitas penunjang bagi pengguna disabilitas untuk mewujudkan kesamaan pada aspek penghidupan dan kehidupan.

Berdasarkan hasil penelitian dan pembahasan mengenai kajian konsep aksesibilitas pada sekolah kejuruan difabel maka dapat disimpulkan bahwa secara umum aksesibilitas pada sekolah tersebut masih ada beberapa kekurangan.

Setelah dilakukan pengamatan pada SLB negeri Bekasi jaya dapat ditarik kesimpulan bahwa SLB tersebut sudah melakukan penerapan 
aksesibilitas yang cukup memadai seperti Ukuran dasar ruang cukup, Jalur pemandu/guiding block sudah memenuhi standar, Jalur pedestrian (entrance) mudah dilalui, Ramp mudah dilalui, Jalur evakuasi yang tertata, toilet sudah memenuhi standar hanya saja kebersihan kurang terjaga.

\section{UCAPAN TERIMAKASIH}

Ucapan terima kasih kepada semua pihak yang telah berperan dalam penelitian ini, pada SLB Negeri Bekasi jaya saya ucapkan terima kasih karena data yang saya per oleh cukup lengkap sehingga dapat dituangkan dalam bentuk tulisan ini.

\section{DAFTAR PUSTAKA}

[1] Mendiknas. (2009) Permendiknas no. 70 tahun Tentang pendidikan inklusif bagi peserta didik yang memiliki kelainan dan memiliki potensi kecerdasan dan/atau bakat istimewa.

[2] Haryanti RH, and Sari C (2017) Aksesibilitas Pariwisata Bagi Difabel di Kota Surakarta (Studi Evaluasi Peraturan Menteri Pekerjaan Umum Nomor 30 Tahun 2006 Tentang Pedoman Teknis Fasilitas Dan Aksesibilitas Pada Bangunan Gedung Dan Lingkungan). Spirit Publik: Jurnal Administrasi Publik Vol. 12, No. 1: Hal. 85-96.

[3] Permen PU 30. (2006) Peraturan Menteri Pekerjaan Umum dan Perumahan Rakyat tentang Pedoman Teknis Fasilitas dan Aksesibilitas pada Bangunan Gedung dan Lingkungan.

[4] Yun JB, Jhang ST, Jhon CS, and Lee CW (2002) Analysis of system performance by changing the ring architecture on the dual ring CC-NUMA system. Dipresentasikan pada Ninth International Conference on Parallel and Distributed Systems, 2002 Proceedings, Hal. 103-108.

[5] Kessler RC, and Üstün TB (2004) The world mental health (WMH) survey initiative version of the world health organization (WHO) composite international diagnostic interview (CIDI). International journal of methods in psychiatric research Vol. 13, No. 2: Hal. 93-121.

[6] Andhi J (2015) IMPLEMENTASI UNDANG-UNDANG NO. 4 TAHUN 1997 TENTANG PENYANDANG CACAT TERHADAP PEMENUHAN HAK ATAS PEKERJAAN DAN PENGHIDUPAN YANG LAYAK. Jurnal Hukum Vol. 2, No. 2: Hal. 133-141.

[7] Sativa S, and Bactiar YB (2020) KAJIAN TERHADAP AKSESIBILITAS FISIK BAGI TUNANETRA DAN TUNADAKSA DI GEDUNG LPPMP UNY. Informasi dan Ekspose hasil Riset Teknik Sipil dan Arsitektur Vol. 16, No. 1: Hal. 85-91.

[8] Permen PUPU No. 14. (2017) Permen PUPR No. 14 Tahun 2017 Tentang Persyaratan Kemudahan Bangunan Gedung. 